\title{
Task Force on Behavior Analysis and Public Policy
}

\section{Executive Council Liaison Commentary}

The following report and recommendations of the Association for Behavior Analysis (ABA) Task Force on Behavior Analysis and Public Policy is the first Task Force document to be published in The Behavior Analyst. The occasion thus invites several comments about the procedures involved in the acceptance and publication of Task Force reports and recommendations, both in the present case and for future ABA Task Forces.

The Task Force on Behavior Analysis and Public Policy was appointed by the ABA Executive Council in May 1986 with the charge to examine how the ABA membership might effectively contribute to public policymaking and thereby contribute to the public interest. Under the leadership of Stephen B. Fawcett, the Task Force members met as a group on several occasions, wrote numerous section drafts, rewrote edited versions of those drafts, submitted preliminary reports to the ABA Executive Council for comment and advice, and prepared and submitted a final report to the Executive Council for its October 1987 meeting. The Executive Council reviewed that report and its accompanying recommendations, and accepted it pending completion of final revisions.

Acceptance by the Executive Council or for publication by the journal editor, though, does not establish this document as official Association policy, as is true of other Task Force reports and recommendations. Official statements of Association policy require approval by the Association's voting membership. Thus, this document, or some further version thereof, must be submitted to and approved by the membership before being distributed as Association policy. The usual mechanism for approval will be to publish an abstracted version of the document in the $A B A$ Newsletter, with the full text available on request, and then to submit the report and recommendations to voting members of the Association for a mail ballot. Only upon majority approval will the document become official Association policy. This approval mechanism is independent of acceptance by the Executive Council or publication of the report in The Behavior Analyst. The following report on Behavior Analysis and Public Policy was submitted to the journal as the work of the Task Force members themselves, and was accepted as such.

In sum, the Executive Council commends the Task Force for its excellent report and thoughtful recommendations. The document, though, does not constitute official Association policy as yet, nor should it be distributed as such.

Edward K. Morris Executive Council Liaison Public Policy Task Force 